\title{
TAREFAS DE ROLE PLAY PROPOSTAS POR TRÊS LIVROS DIDÁTICOS DE INGLÊS COMO LÍNGUA ESTRANGEIRA
}

\author{
Caroline Comunello* \\ Aline Paulino da Rosa * \\ Daniela Moraes do Nascimento *
}

\begin{abstract}
RESUMO: O objetivo do trabalho é analisar atividades de role play em três livros didáticos de inglês como língua estrangeira. A análise verificou o número de alunos envolvidos, gêneros orais utilizados, pré-determinação de estruturas e vocabulário e local onde as atividades estão inseridas. Os dados revelam que as atividades são predominantemente voltadas para duplas. Os gêneros orais trabalhados são bastante variados e estão adequados à faixa etária dos alunos. Além disso, verificamos que, à medida que as unidades avançam, encontramos um local específico onde elas estão inseridas. Concluímos que essas tarefas abrangem uma grande variedade de situações autênticas de uso que podem oferecer oportunidades ricas para o desenvolvimento da produção oral dos alunos, levando-os a interagirem na LE de maneira significativa.
\end{abstract}

PALAVRAS CHAVE: Livros didáticos - Produção oral - Role play

ABSTRACT: This paper aims at analyzing role play activities from three books of English as a foreign language. The analysis was based on the number of students involved, types of genre, previous selection of structures or vocabulary and section of the book where the activity is presented. The data show that the majority of the activities are designed to be used by pairs of students. There is a great variety of oral genre and they are appropriate to the age of the students. Furthermore, it was possible to identify that in each of the last lessons there is a place destined to present them. Conclusively, the role play activities comprise a great variety of authentic situations that aim at the development of learners' oral production, providing them meaningful opportunities of interaction in the foreign language.

KEYWORDS: Books - Oral production - Role play

\section{INTRODUÇÃO}

Grande parte das análises de livros didáticos de Língua estrangeira (LE) são dirigidas à avaliação das atividades textuais e gramaticais dos mesmos, deixando-se de lado um aspecto da aprendizagem que tem um papel fundamental para os propósitos da grande maioria dos alunos: as atividades de produção oral. Se questionados a respeito de seus objetivos quanto ao aprendizado de um segundo idioma, uma grande amostra dos aprendizes responderá que tem como objetivo falar, se fazer entender, se comunicar na língua alvo. Com isso, acreditamos ser de extrema importância uma discussão acerca das atividades destinadas ao trabalho da oralidade apresentadas por alguns livros didáticos. As atividades apresentadas por eles realmente contribuem para $o$

\footnotetext{
* Alunas do Programa de Pós-Graduação em Letras da UFRGS. E-mails: carolcomunello@yahoo.com, alinerosa@gmail.com, danielamoraes11@yahoo.com.br.
} 
desenvolvimento da competência comunicativa dos alunos? De que maneira isso é feito? Elas exploram a diversidade da língua alvo?

Marcuschi, ao se referir aos livros didáticos de língua portuguesa, faz uma asserção que pode ser perfeitamente relacionada ao trabalho da linguagem oral também nos livros didáticos de língua estrangeira. Nessa asserção ele diz que:

[...] os autores dos manuais didáticos, em sua maioria, ainda não sabem onde e como situar o estudo da fala. Certamente não se trata de ensinar a falar, trata-se de identificar a imensa riqueza e variedade de usos da língua (2001, p. 22).

Até que ponto as tarefas propostas para a prática da oralidade, tão sonhada pelos aprendizes, são trabalhadas de maneira eficaz nos livros didáticos? Que gêneros são explorados nas atividades? Segundo Pinto (2003, p. 87), nas situações escolares os alunos desenvolvem a capacidade de utilizar adequadamente os gêneros de acordo com as situações de comunicação em que estiverem inseridos. $\mathrm{O}$ role play mostra-se então como uma ótima oportunidade para que as mais variadas situações de uso da língua sejam ensaiadas pelos aprendizes.

Com o propósito inicial de analisarmos as atividades de produção oral presentes em livros didáticos de inglês como LE, começamos a folhear alguns livros com o objetivo de localizar possíveis aspectos salientes e recorrentes dessas atividades. Verificamos que além de propostas para debates e discussões de perguntas pertinentes aos tópicos apresentados, um tipo específico de atividade mostrou-se recorrente: as atividades de role play. Percebemos que os livros mais recentes, embasados na abordagem comunicativa, aboliram de certa forma o uso dos chamados diálogos didáticos, tão comuns na maioria dos materiais há alguns anos. Segundo Chiarette (1994), as atividades de role play são oriundas desses diálogos, classificados por Canale e Swain como diálogos comunicativos (apud Chiarette, 1994) que se constituem em torno das funções comunicativas (convidar, apresentar-se, obter informações, etc.) de tal modo que o aprendiz faça uso adequado das mesmas em formas gramaticais específicas.

Alguns desses diálogos são artificiais, muito distantes da linguagem utilizada em situações reais de interação, cumprem exclusivamente o objetivo de apresentar estruturas e vocabulário novo e algumas vezes acabam por não ter sentido nenhum. Sobre isso Chiarette afirma que: "há materiais didáticos que adotam uma organização do conteúdo gramatical tão ostensiva que melhor seria referir-se a itens gramaticais em forma de diálogos ao invés de diálogos gramaticais" (1994, p. 157).

Tínhamos a expectativa, então, de que as atividades de role play apresentadas pelos livros seguiriam o formato e a função atribuída aos diálogos descritos acima. Nesse sentido, essas atividades seriam uma mera prática controlada sem um fim comunicativo mais abrangente, cumprindo basicamente a função de fazer com que o aluno produza o conteúdo desejado, não levando em consideração uma provável aplicação desses conhecimentos em situações reais de comunicação. Um exame mais detalhado de 3 livros de inglês como língua estrangeira contrariou as nossas expectativas iniciais. $\mathrm{O}$ que encontramos durante a pesquisa foram atividades bem elaboradas, adequadas ao público-alvo da série didática ao qual o livro pertence e realmente capazes de contribuir para o desenvolvimento da produção oral dos aprendizes.

A escolha dos livros para análise se justifica pela diversidade de contextos de atuação de cada uma de nós: escola particular, curso livre e trabalho com alunos 
particulares. Assim, tivemos a idéia de comparar as atividades de role play dos materiais didáticos utilizados por nós em áreas de atuação tão diferentes. Selecionamos um livro de cada contexto de ensino que fosse destinado ao mesmo nível de conhecimento lingüístico, a saber, estudantes de nível pré-intermediário: American Headway 3 - Student Book, da editora Oxford, utilizado por alunos do $3^{\circ}$ ano de uma escola particular; CEP Pre-Intermediate 3 - Student book, do Yázigi, utilizado por alunos desse curso; e Market Leader - Course Book Pre-Intermediate, da editora Longman, utilizado com alunos particulares da área de business.

\section{METODOLOGIA}

Primeiramente, como os materiais propõem uma grande quantidade de atividades que já vêm caracterizadas como tarefas de role play, discutimos as características constitutivas das mesmas para, assim, podermos fazer a seleção e classificação das tarefas apresentadas pelos três livros. Como o próprio nome sugere, essas atividades são configuradas de maneira que os aprendizes desempenhem papéis específicos, relevantes para a aplicação dos conhecimentos trabalhados ao longo das unidades. Segundo Livingstone (1983), "o role play é uma atividade que dá ao aluno a oportunidade de praticar a língua, aspectos comportamentais e papéis reais que ele pode precisar fora da sala de aula" (p. 6). De modo a nos auxiliar na análise e nas conclusões da pesquisa, iniciamos um processo de elaboração de critérios para avaliar as atividades. $\mathrm{O}$ que pode ser chamada de uma boa atividade de role play? Que critérios podem ser utilizados nesta avaliação? Ao discutir essas perguntas, elaboramos uma lista a fim de avaliarmos as tarefas, considerando que a atividade de role play deve:

- Estar de acordo com o nível lingüístico e idade dos aprendizes;

- Respeitar os interesses e necessidades dos alunos;

- Propiciar situações variadas a fim de fazer com que o aluno coloque em prática o que foi aprendido, preparando-o para situações na vida real;

- Ter um objetivo claro de maneira a não confundir o aluno;

- Apresentar, obrigatoriamente, em níveis mais básicos, um guia de estruturas e/ou vocabulário para auxiliar o aluno na elaboração da sua produção.

Após a seleção de todas as atividades encontradas nos três livros, iniciamos a análise levando em consideração as perguntas norteadoras da pesquisa:

1. Como é apresentada a atividade de role play nos três livros didáticos?

$1.1 \mathrm{O}$ role play é uma tarefa para ser realizada em duplas ou as atividades propostas abrem a possibilidade de haver interação entre um maior número de participantes?

1.2 Quais gêneros são propostos nas atividades?

1.3 As situações apresentadas nessas atividades são compatíveis com a faixa etária dos alunos?

2. Existe alguma indicação de estruturas e/ou vocabulário que devem ser utilizados(as) na atividade de maneira a caracterizá-la como mera prática controlada?

2.1 Em caso afirmativo, de que maneira isso é feito?

3. Em qual parte da unidade a tarefa de role play é apresentada?

3.1 Existe uma justificativa pedagógica apresentada pelo livro do professor para a inserção do role play no local onde ele é apresentado? 


\section{AMERICAN HEADWAY 3}

O livro é dividido em 12 unidades apresentando um total de 6 tarefas de role play que abrangem basicamente dois gêneros orais, sendo eles: entrevistas de emprego (2) e conversas informais (4). As conversas informais têm como interlocutores amigos e familiares além de funcionários de hotéis e de restaurantes. As funções desempenhadas nos gêneros da conversa informal são: obtenção de informações, elaboração de sugestões e interrupção da conversa.

Todas as atividades propostas são dirigidas a pares de alunos, onde a cada um é designado o papel: aluno A e aluno B, sendo que em uma das tarefas os alunos têm a opção de escolher qual a situação que gostariam de dramatizar. Um aspecto que consideramos um pouco desfavorável é que em três das atividades os alunos têm muitas situações a serem dramatizadas, o que pode acabar ocasionando falta de motivação para levar a atividade adiante, como no exemplo abaixo:

(Fonte: SOARS, 2003, p. 41)

Figura 1 - Exemplo de atividade de role play no livro American Headway 3

Obviamente, o professor deve usar o bom senso e verificar o grau de motivação dos alunos em relação à atividade e, caso necessário, solicitar que, ao invés de dramatizarem todas as situações propostas, sugerir que escolham três que acharem mais interessantes para fazê-lo.

Levando-se em consideração o fato de este livro ser utilizado em uma escola particular, onde muitos alunos têm a oportunidade de viajar para países onde vivenciarão as situações propostas no livro, aliado ao fato de que esses alunos estão no $3^{\circ}$ ano do ensino médio e em breve poderão vivenciar situações de entrevista de emprego, é possível afirmar que as situações de role play apresentadas no livro estão adequadas à faixa etária, interesse e necessidade dos aprendizes.

Quanto à pré-determinação de estruturas e vocabulário nas atividades, constatamos que em somente uma delas há a indicação de palavras a serem usadas na interação. Nas tarefas restantes, as situações de dramatização são apresentadas, mas os alunos podem resolvê-las utilizando a linguagem e o vocabulário que acharem adequado. $\mathrm{O}$ que o exercício traz é algum tipo de exemplo com alguma das situações propostas ou ainda exemplos de perguntas que podem ser utilizadas na tarefa. $\mathrm{Na}$ atividade em que há a indicação de palavras, essas serviriam como um guia para que os alunos estabeleçam a interação. $\mathrm{O}$ foco da atividade está nas trocas interacionais e na conclusão da tarefa, não podendo de maneira alguma ser caracterizada como prática controlada de estruturas previamente trabalhadas.

(Fonte: SOARS, 2003, p. 33)

Figura 2 - Exemplo de atividade de role play no livro American Headway 3 
As tarefas estão inseridas ao final das unidades, mais especificamente na seção denominada Practice. As poucas ocorrências de atividades de role play são justificadas pelo fato de o livro apresentar muitos outros momentos de prática da linguagem oral em todas as unidades, incluindo atividades como: o que você acha?, fale sobre você e uma seção exclusivamente destinada a Speaking.

Não existe uma justificativa fornecida pelo manual do professor acerca da inserção das atividades em questão nas seções onde elas se encontram. Concluímos, entretanto, que isso ocorra devido ao fato de essas seções estarem localizadas no final das unidades, partindo-se do pressuposto de que os alunos já trabalharam com as estruturas e vocabulário necessários para a realização da tarefa.

\section{CEP 3 - COMMUNICATIVE ENGLISH PRACTICE}

O livro é divido em 6 unidades e apresenta 7 tarefas de role play organizadas nos seguintes gêneros: conversa informal, entrevista, conversa telefônica e consulta médica e, assim como verificado no livro anterior, todas as tarefas são propostas para serem realizadas em duplas.

Os gêneros trabalhados no livro são bastante variados e as situações propostas são bastante abrangentes, de maneira a contemplar os diferentes tipos de alunos que utilizarão o material. No contexto de curso livre, como os alunos são agrupados por níveis de conhecimento, é freqüente a ocorrência de alunos adolescentes e adultos dividindo a mesma sala. Desta maneira, como o material foi elaborado para ser desenvolvido exclusivamente no curso livre onde essa realidade está presente - públicoalvo extremamente variado - não há como prever de maneira precisa as necessidades e interesses dos aprendizes. O professor tem, então, todo um trabalho de adaptar as suas atividades respeitando os interesses típicos das faixas etárias de seus alunos. Contudo, em algumas das atividades de role play utilizadas no livro CEP, há a proposta de realização de duas atividades diferentes, para que o aluno possa escolher a que mais lhe agrada. Assim, não há a inadequação de um adolescente ter de dramatizar uma reunião de trabalho ou entrevista de emprego, por exemplo.

(Fonte: LOPES ET AL, 2003, p. 30)

Figura 3 - Exemplo de atividade de role play no livro CEP 3

(Fonte: LOPES ET AL, 2003, p. 31)

Figura 4 - Exemplo de atividade de role play no livro CEP 3

A atividade acima é um exemplo de tarefa na qual os alunos podem optar pela situação que irão encenar. Um aluno adulto, que está estudando inglês com objetivos profissionais, pode escolher trabalhar com a primeira opção, que aborda uma interação 
no ambiente de trabalho. Um aluno adolescente, por sua vez, pode optar pela segunda situação, falando de algo do interesse da maioria dos adolescentes, as férias.

As funções desempenhadas pelas tarefas apresentadas são as mais variadas: convidar alguém para sair, obter informações, apresentar-se, falar a respeito das férias, entrevistar alguém e explicar um problema a um médico.

As tarefas de role play são propostas com a apresentação das situações e divisão das tarefas para os alunos A e B, mas não há nenhum tipo de modelo, obrigatoriedade de uso de estruturas ou vocabulário a serem empregados na atividade. Os alunos podem realizar a atividade como acharem melhor tendo por base o conhecimento adquirido sobre o assunto ao longo da unidade.

Cinco das atividades estão concentradas nas duas primeiras unidades, uma na unidade 3 e uma na última unidade. Não há argumentação no manual do professor justificando a disposição das atividades, mas isso possivelmente ocorre devido à ênfase dada às habilidades de escrita e leitura nas primeiras seções da unidade, o que acarreta um conhecimento maior acerca do assunto abordado que serve como base para a produção oral que é feita em um estágio posterior.

\section{MARKET LEADER}

O livro apresenta um total de 24 atividades de role play uniformemente divididas em 12 unidades, somando assim, duas atividades por unidade. A primeira atividade de role play de cada unidade é apresentada na seção Skills, a qual explora intensamente as habilidades auditivas e de fala através de exercícios auditivos variados, tais como apresentações, reuniões, debates, conferências, conversas telefônicas, e, no tocante à produção oral, propõe discussões, entrevistas, apresentações de produtos, conversas sobre o cotidiano, além das atividades de role play propriamente ditas. A segunda atividade de role play de cada unidade é sempre apresentada na página seguinte à seção de Skills. Essa, por sua vez, é chamada de Task e envolve predominantemente atividades em grupo, sendo que o assunto da atividade está diretamente relacionado ao texto que a precede.

O número de participantes envolvidos em cada atividade é um dos grandes diferenciais do livro. Das 24 atividades propostas, 9 delas envolvem trabalhos em duplas, 13 envolvem trabalhos em grupo e, o que se mostrou bastante interessante, duas das atividades propõem tarefas que em um primeiro momento envolvem dramatizações em duplas com objetivos específicos e posteriormente as duplas devem se unir a outros grupos para a conclusão da atividade, como no caso do exemplo a seguir:

(Fonte: COTTON; FALVEY \& KENT, 2003, p. 97)

Figura 5 - Exemplo de atividade de role play no livro Market Leader

Nessa atividade, apesar da complexidade da situação apresentada (ler a descrição do seu papel, preparar-se para a reunião, negociar, comparar as decisões, tentar persuadir os demais colegas), a explicação para a execução da atividade é fornecida de maneira simples e clara, contribuindo para que os alunos tenham uma boa compreensão 
acerca dos objetivos da atividade. Assim, os alunos são capazes de perceber exatamente o momento em que conseguiram completar a tarefa.

A primeira tarefa de role play proposta em cada unidade é sempre acompanhada de um quadro denominado useful language onde são encontradas expressões da linguagem que de fato são utilizadas em situações reais de conversação no contexto sugerido pela atividade, como pode ser observado no exemplo abaixo:

(Fonte: COTTON; FALVEY \& KENT, 2003, p. 39)

Figura 6 - Exemplo do quadro useful language no livro Market Leader

Já na segunda atividade de role play proposta em cada unidade, geralmente não há uma indicação de estruturas, expressões ou vocabulário a serem empregados, mas em algumas delas, além dos cartões com a descrição dos papéis dos participantes, há outros tipos de suporte que os alunos podem utilizar como apoio no momento da produção, como a pauta para a reunião.

Assim como nos livros anteriores, o manual do professor não fornece uma explicação acerca da disposição da atividade na unidade.

Há uma grande diversidade de gêneros trabalhados nas atividades, sendo eles: conversa telefônica (2), discussão (12), negociação (2), apresentação de produto / empresa (3), conversa informal (2) e decisão acerca de um assunto (3).

Os gêneros são muito bem explorados, uma vez que em se tratando de alunos de inglês para negócios, os aprendizes tendem a utilizar a língua em uma vasta gama de situações para uma infinidade de propósitos. Ao mesmo tempo em que precisam estar preparados para conduzir uma reunião na língua alvo, precisam ainda dominar o idioma para se engajarem em uma conversa informal sobre a comida de um restaurante, por exemplo. Além disso, diferentemente de alunos que precisam do inglês para se comunicar exclusivamente em viagens, esses alunos precisam saber interagir com um grande número de participantes de maneira a alcançar seus objetivos no ramo de negócios. Precisam ter o conhecimento necessário para apresentarem suas propostas, contra-argumentar, discordar, fechar contratos, entre outras coisas. Com base na análise das tarefas de role play propostas pelo livro, concluímos que essas são bastante apropriadas para o desenvolvimento das habilidades necessárias para a execução dessas tarefas e encaixam-se perfeitamente nas necessidades e interesses desses aprendizes.

\section{CONCLUSÕES}

Quadro geral comparativo das atividades de role play nos três livros:

Tabela 1 - Atividades de role play nos livros analisados

\begin{tabular}{|c|c|c|c|}
\hline & $\begin{array}{c}\text { American } \\
\text { Headway 3 }\end{array}$ & CEP 3 & Market Leader \\
\hline Número de & 6 & 8 & 24 \\
\hline
\end{tabular}




\begin{tabular}{|c|c|c|c|}
\hline atividades & & & \\
\hline $\begin{array}{c}\text { Número de } \\
\text { unidades }\end{array}$ & 12 & 6 & 12 \\
\hline $\begin{array}{l}\text { Gêneros orais } \\
\text { empregados nas } \\
\text { atividades }\end{array}$ & $\begin{array}{c}\text { Conversa informal } \\
\text { (4) } \\
\text { Entrevista (2) }\end{array}$ & $\begin{array}{c}\text { Conversa informal } \\
\text { (2) } \\
\text { Entrevista (1) } \\
\text { Conversa telefônica } \\
\text { (1) } \\
\text { Consulta médica (1) }\end{array}$ & $\begin{array}{c}\text { Conversa informal } \\
\text { (1) } \\
\text { Negociação (2) } \\
\text { Conversa telefônica } \\
\text { (4) } \\
\text { Discussão e decisão } \\
\text { final (14) } \\
\text { Apresentação de um } \\
\text { produto (3) }\end{array}$ \\
\hline
\end{tabular}

Após a análise dos três livros, percebemos que as atividades de role play são bem estruturadas e podem contribuir de maneira significativa para o desenvolvimento da linguagem oral dos aprendizes, uma vez que trabalham gêneros variados condizentes com a proposta e público alvo dos livros, e contam com uma grande variedade de interlocutores, objetivos e funções.

Os três livros propõem ótimas tarefas de role play, mas o Market Leader pode ser destacado pela diversidade de gêneros abordados e por apresentar, apesar da regularidade das atividades - duas por unidade -, situações criativas, originais e relevantes para a realidade dos alunos. Além disso, o envolvimento de um número maior de participantes nas atividades e a abordagem de assuntos que geram discussão torna a tarefa mais dinâmica e próxima da realidade. Os alunos são muito bem informados quanto aos seus papéis na atividade, e em alguns casos, ainda têm como apoio outro tipo de material (pauta da reunião, memorando, etc.), facilitando assim a elaboração da sua produção.

Consideramos as atividades apresentadas nos três livros bastante válidas, pois as trocas interacionais entre pares simulam situações que podem realmente vir a acontecer no dia-a-dia, diferentemente de situações que não contribuem para um comportamento mais espontâneo dos alunos, tal como: "fale da sua família ou converse com seu colega sobre o que você achou do texto". Além disso, as tarefas de produção oral, em especial as de role play, que são objeto de análise desse estudo, são condizentes com os objetivos propostos nos livros para o desenvolvimento da oralidade, além de estarem de acordo com os interesses dos aprendizes aos quais os livros são direcionados. Essas conclusões estão de acordo com o que MacCarthy \& O'Keeffe afirmam sobre as atividades de produção oral: "As atividades de fala não devem ocorrer em um vácuo, separadas da vida social e cultural dos aprendizes" (2004, p. 36).

\section{REFERÊNCIAS}


CHIARETTE, Avany P. (1994) A performance do diálogo no livro de inglês: evolução e limites do gênero. 1994. Tese (Doutorado em Letras) - Programa de Pós-Graduação em Letras UFMG. Belo Horizonte. p. 153-174

COTTON, David; FALVEY, David; KENT, Simon. Market Leader Course Book: Preintermediate Business English. Essex: Longman, 2003. 160 p.

COTTON, David; FALVEY, David; KENT, Simon. Market Leader Teacher's Book: Pre-intermediate Business English. Essex: Longman, 2003. 185 p.

LIVINGSTONE, Carol. Role play in language learning. Essex: Longman, 1983. 94 p.

LOPES et al. CEP 3: Communicative English Program Pre-Intermediate. Brazil: Yázigi, 2003. $103 \mathrm{p}$.

MacCARTHY, Michael \& O'KEEFFE, Anne (2004) Research in the teaching of speaking. Annual Review of Applied Linguistics, 24: 26-43.

MARCUSCHI, Luiz Antônio (2001a) Oralidade e ensino de língua: uma questão pouco "falada". In: Dionisio, Angela P. \& Bezerra, Maria A. (orgs.) O livro didático de português: múltiplos olhares. Rio de janeiro: Lucerna. p. 19-32

PINTO, Abuêndia Padilha. Gêneros discursivos e ensino da língua inglesa. In: Dionisio, Angela P. \& Bezerra, Maria A. (orgs.) Gêneros textuais e ensino. Rio de Janeiro: Lucerna. $2^{\text {a }}$ ed. p. 87.

SOARS, Liz \& John. American Headway 3: student book. New York: Oxford, 2003. $154 \mathrm{p}$.

SOARS, Liz \& John. American Headway 3: teacher's book. New York: Oxford, 2003. $166 \mathrm{p}$. 